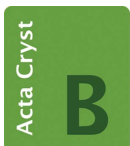

STRUCTURAL SCIENCE CRYSTAL ENGINEERING MATERIALS

ISSN 2052-5206

Received 10 September 2018

Accepted 18 December 2018

Edited by A. Katrusiak, Adam Mickiewicz University, Poland

Keywords: rare-earth oxides; polymorphism; surface morphology; X-ray diffraction; nanostructures; molecular beam epitaxy.

Supporting information: this article has supporting information at journals.iucr.org/b

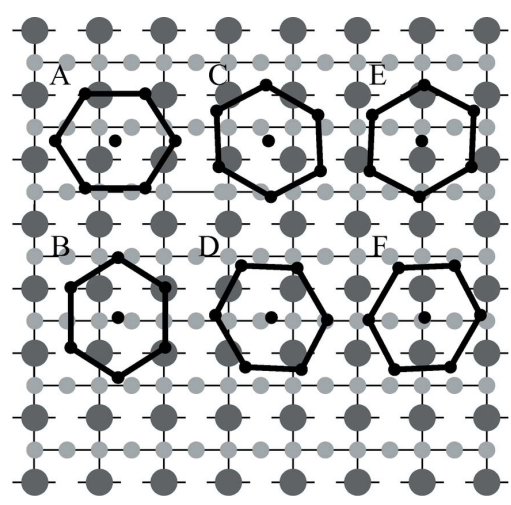

C 2019 International Union of Crystallography

\section{Influence of nanostructure formation on the crystal structure and morphology of epitaxially grown $\mathrm{Gd}_{2} \mathrm{O}_{3}$ on $\mathrm{Si}(001)$}

\author{
Philipp Gribisch,* Jan Schmidt, Hans-Jörg Osten and Andreas Fissel
}

Institute of Electronic Materials and Devices, Leibniz Universität Hannover, Schneiderberg 32, Hannover, 30167, Germany. ${ }^{*}$ Correspondence e-mail: gribisch@mbe.uni-hannover.de

The influence of growth conditions on the layer orientation, domain structure and crystal structure of gadolinium oxide $\left(\mathrm{Gd}_{2} \mathrm{O}_{3}\right)$ on silicon (001) has been investigated. $\mathrm{Gd}_{2} \mathrm{O}_{3}$ was grown at low $\left(250^{\circ} \mathrm{C}\right)$ and high $\left(850^{\circ} \mathrm{C}\right)$ temperatures with different oxygen partial pressure as well as a temperature ramp up during growth. At low temperature, the cubic bixbyite type of crystal structure with space group $I a \overline{3}$ was grown at low oxygen partial pressure. The layers consist of two domains oriented orthogonal to each other. The epitaxial relationships for the two domains were found to be $\mathrm{Gd}_{2} \mathrm{O}_{3}(110)[001] \| \mathrm{Si}(001)[110]$ and $\mathrm{Gd}_{2} \mathrm{O}_{3}(110)[001] \| \mathrm{Si}(001)[\overline{1} 10]$, respectively. Applying additional oxygen during growth results in a change in crystal and domain structures of the grown layer into the monoclinic $\mathrm{Sm}_{2} \mathrm{O}_{3}$-type of structure with space group $C 2 / m$ with $(20 \overline{1})$ orientation and mainly two orthogonal domains with the epitaxial relationship $\mathrm{Gd}_{2} \mathrm{O}_{3}(20 \overline{1})[010] \| \mathrm{Si}(100)\langle 110\rangle$ and a smooth surface morphology. Some smaller areas have two intermediate azimuthal orientations between these variants, which results in a six-domain structure. The change in crystal structure can be understood based on the Gibbs-Thomson effect caused by the initial nucleation of nanometre-sized islands and its variation in diameter with a change in growth conditions. The crystal structure remains stable even against a temperature ramp up during growth. The layers grown at high temperature exhibit a nanowire-like surface morphology, where the nanowires have a cubic crystal structure and are aligned orthogonal to each other along the $\langle 110\rangle$ in-plane directions. An increase in oxygen supply results in a reduced length and increased number of nanowires due to lower adatom mobility. The results clearly indicate that both kinetic and thermodynamic factors have a strong impact on the crystal structure, epitaxial relationship and morphology of the grown layers.

\section{Introduction}

Rare-earth oxides (REOs) have gained a lot of interest in recent years because of their usage in several applications (Charalampides et al., 2015), such as catalysts in the automotive industry to replace precious metals and as an additive in glass industry for improving the optical properties and chemical stability (Wang et al., 2012; Weber et al., 2004). Moreover, rare-earth oxides are utilized in ceramics to produce hydrophobic surfaces and as additives for batteries to enhance their performance (Tanaka et al., 2006; Azimi et al., 2013). Furthermore, sesquioxides of lanthanides have a great potential in the utilization in high-energy solid-state laser systems and scintillators (Druon et al., 2013; Rétot et al., 2011). In microelectronics they could be used as an alternative gate dielectric to substitute $\mathrm{SiO}_{2}$ in metal oxide semiconductor (MOS) transistors (Gottlob et al., 2006). 
The applicability of REOs depends on their physical properties, such as ionicity, dielectric properties, band gap and their surface morphology. REOs reveal polymorphism, where for example the dielectric properties of the polymorphic structures differ (Edge et al., 2008). Regarding the electrical application, the crystal structure and orientation can influence the properties of the rare-earth oxide/silicon interface, for example by formation of interface dipoles, which could improve the performance of MOS structures significantly (Huang et al., 2012). Since the crystal structure of REOs depends on the manufacturing conditions (Foëx \& Traverse, 1966), it is useful to investigate how the manufacturing parameters influence the structural and morphological properties of rare-earth oxides.

In this work, $\mathrm{Gd}_{2} \mathrm{O}_{3}$ grown on $\mathrm{Si}(001)$ was chosen as a prototypical material system. $\mathrm{Gd}_{2} \mathrm{O}_{3}$ is thermodynamically stable in contact with silicon and has a good lattice match and can therefore be grown epitaxially (Hubbard \& Schlom, 1996). Besides the epitaxy on silicon, $\mathrm{Gd}_{2} \mathrm{O}_{3}$ was also grown on $\mathrm{GaAs}$ for MOS application and exhibits a good passivation behaviour in a compound with gallium oxide $\left(\mathrm{Ga}_{2} \mathrm{O}_{3}\right)$ (Chiu et al., 2011; Hong et al., 2000; Kwo et al., 1999).

$\mathrm{Gd}_{2} \mathrm{O}_{3}$ can either be amorphous or exist in a crystalline phase (Kwo et al., 2001). For the crystalline phase, three different polymorphs are known to exist for $\mathrm{Gd}_{2} \mathrm{O}_{3}$ : the cubic bixbyite C-type $\left(\mathrm{Mn}_{2} \mathrm{O}_{3}\right.$ type of structure) with space group $I a \overline{3}$, the hexagonal A-type $\left(\mathrm{La}_{2} \mathrm{O}_{3}\right.$-type of structure) with space group $P \overline{3} m 1$ and the monoclinic B-type $\left(\mathrm{Sm}_{2} \mathrm{O}_{3}\right.$-type of structure) with space group $C 2 / m$ (Zinkevich, 2007). From here on the different crystal structures will be termed cubic, monoclinic and hexagonal, respectively. For bulk material and standard conditions only the cubic structure is observed. At high pressure and/or high temperature the crystal structure transforms to the hexagonal or monoclinic structure (Zinkevich, 2007). In contrast, several reports about the preparation of non-cubic $\mathrm{Gd}_{2} \mathrm{O}_{3}$ in thin layers at lower temperature and/or atmospheric pressure are found in literature, which we will briefly address in the following.

Thin films of $\mathrm{Gd}_{2} \mathrm{O}_{3}$ were found to show a thicknessdependent change of the crystal phase from hexagonal to monoclinic structure during epitaxial growth on $\mathrm{GaN}, \mathrm{SiC}$ and GaAs (Chang et al., 2013; Fissel et al., 2006a; Chiang et al., 2014). The epitaxial growth of $\mathrm{Gd}_{2} \mathrm{O}_{3}$ on $\mathrm{Si}(111)$ at a low temperature results in a non-cubic structure (Moellers et al., 2017). On $\mathrm{Ge}(001)$ a mixture of the cubic and monoclinic phase of crystalline $\mathrm{Gd}_{2} \mathrm{O}_{3}$ was observed (Molle et al., 2008). On the industrially relevant $\mathrm{Si}(001)$ substrates, epitaxial growth of $\mathrm{Gd}_{2} \mathrm{O}_{3}$ results usually in the formation of the cubic phase in (110) orientation (Osten et al., 2008). But other growth experiments also show the appearance of the monoclinic phase after the sputter deposition or laser molecular beam epitaxy on $\mathrm{Si}(001)$, depending on the growth conditions (oxygen chemical potential and temperature) (Li et al., 2004; Xiang et al., 2013). Systematic investigations on the general conditions for stabilization of a specific polymorph are scarcely available. The same is also true for more general understanding on the mechanisms responsible for the appearance of certain crystal phases in thin layers of REOs.

Here we report on the influence of growth conditions, such as temperature $(T), T$ change during growth and oxygen partial pressure on the crystal structure and morphology of $\mathrm{Gd}_{2} \mathrm{O}_{3}$ layers. The layers were grown on $\mathrm{Si}(001)$ using molecular beam epitaxy (MBE). The MBE technique provides the opportunity to grow the $\mathrm{Gd}_{2} \mathrm{O}_{3}$ far away from thermodynamic equilibrium and to reduce the incorporation of impurities due to the ultra-high vacuum. The layer structure and morphology was investigated in detail using several characterization methods. The results of growth experiments are discussed within the framework of nucleation theory and phase instability in nanostructures, which could help in understanding hierarchical polymorphs related to the preparation conditions. The results also show a suitable way to prepare different $\mathrm{Gd}_{2} \mathrm{O}_{3}$ polymorphs at conditions far away from thermodynamic equilibrium and under high pressure.

\section{Experimental}

All $\mathrm{Gd}_{2} \mathrm{O}_{3}$ layers were grown on $100 \mathrm{~mm}$ (diameter) n-type silicon (001) substrates $(0.5-0.75 \Omega \mathrm{cm})$ with a high purity of $11 \mathrm{~N}$ for the undoped Si-based material using a multi-chamber MBE system (DCA Instruments) with an average growth rate of about $0.2 \mathrm{~nm} \mathrm{~min}{ }^{-1}$. Before transferring into the growth chamber, the substrates were chemically cleaned with ozone treatment and HF-last to remove the native oxide and organic impurities on the surface. The source material was granular $\mathrm{Gd}_{2} \mathrm{O}_{3}$ which was evaporated with an electron beam. Furthermore, additional oxygen ( $6 \mathrm{~N}$ purity) was introduced in the growth chamber using a piezo leakage valve to stabilize the oxygen partial pressure during growth. The additional oxygen is used to prevent silicide formation due to the oxygen depletion of the $\mathrm{Gd}_{2} \mathrm{O}_{3}$ source material to realize epitaxial growth of stoichiometric $\mathrm{Gd}_{2} \mathrm{O}_{3}$ (Bierwagen et al., 2013). The oxygen supply was started shortly after the beginning of the $\mathrm{Gd}_{2} \mathrm{O}_{3}$ growth, so that silicon surface passivation by $\mathrm{SiO}_{2}$ formation is prevented. Moreover, the oxygen partial pressure during the growth was below $10^{-6}$ mbar, which is low enough to prevent oxidation of the silicon surface. The thickness of the layer was measured using X-ray reflectivity (XRR). Highresolution X-ray diffraction (HRXRD) measurements as symmetric $2 \theta / \omega$ scans were obtained using a Bruker AXS D8 Discover diffractometer in Bragg-Brentano geometry with an asymmetrical $\mathrm{Ge}(220)$ four-bounce Bartels monochromator to select the $\mathrm{Cu} K \alpha_{1}$ radiation $(\lambda=0.154059 \mathrm{~nm})$ for investigating the crystal phase and orientation of the layers. For further studies on the crystal structure, grazing-incidence X-ray diffraction (GIXRD) and azimuthal $\varphi$ scans were performed, where the measurement setup does not allow the monochromator to be inserted and so both the $\mathrm{Cu} K \alpha_{1}$ and $\mathrm{Cu} K \alpha_{2}$ radiation $(\lambda=0.154443 \mathrm{~nm})$ are present during the measurements. Evaluation of all XRD measurements was made using the software OriginPro from OriginLab and the approximation of XRR measurements was made using the software Leptos (Bruker). For monitoring the layer growth and deter- 
mining the surface structure, we used a reflection high-energy electron diffraction (RHEED) setup from Staib Instruments with a CCD camera for imaging purpose. Atomic force microscopy (AFM) in contact mode was performed using using the Autoprobe 5 from Park Scientific AFM Instruments to study the surface morphology. For the analysis of the AFM images the software Gwyddion (GPL free software) was used.

\section{Results}

\subsection{Low-temperature growth}

In a first set of experiments, layers were grown at $250^{\circ} \mathrm{C}$ and a pressure of $5 \times 10^{-8} \mathrm{mbar}$. The growth started on an $\mathrm{Si}(001)$ substrate which showed no surface reconstruction, as revealed by RHEED. In some experiments additional oxygen was supplied, resulting in a total pressure of $2 \times 10^{-7}$ mbar. Furthermore, the impact of a temperature ramp up with $10 \mathrm{~K} \mathrm{~min}^{-1}$ from $250^{\circ} \mathrm{C}$ to $650^{\circ} \mathrm{C}$ during the crystal growth of the $\mathrm{Gd}_{2} \mathrm{O}_{3}$ with additional oxygen was also investigated.

The RHEED image of the layer grown without additional oxygen shows a streaky pattern which indicates a smooth surface [Fig. 1(a)]. The pattern shows double spots besides the main reflection 00, which is typical for growth in (110) orientation in two orthogonal domains as explained later.

In contrast, the RHEED image of the layers grown at $250^{\circ} \mathrm{C}$ with additional oxygen shows a streaky but diffusive pattern with broad intensity maxima [Fig. 1(b)]. In general peak broadening could originate because of a limited thickness of the film and/or a low crystallinity. Since the film thickness of all layers is nearly constant it can be suggested that peak broadening results from lower crystallinity. The RHEED pattern from the sample grown with additional oxygen and temperature ramp up from $250^{\circ} \mathrm{C}$ with $10 \mathrm{~K} \mathrm{~min}^{-1}$ to $650^{\circ} \mathrm{C}$ during the growth [Fig. 1(c)] is almost identical to the RHEED
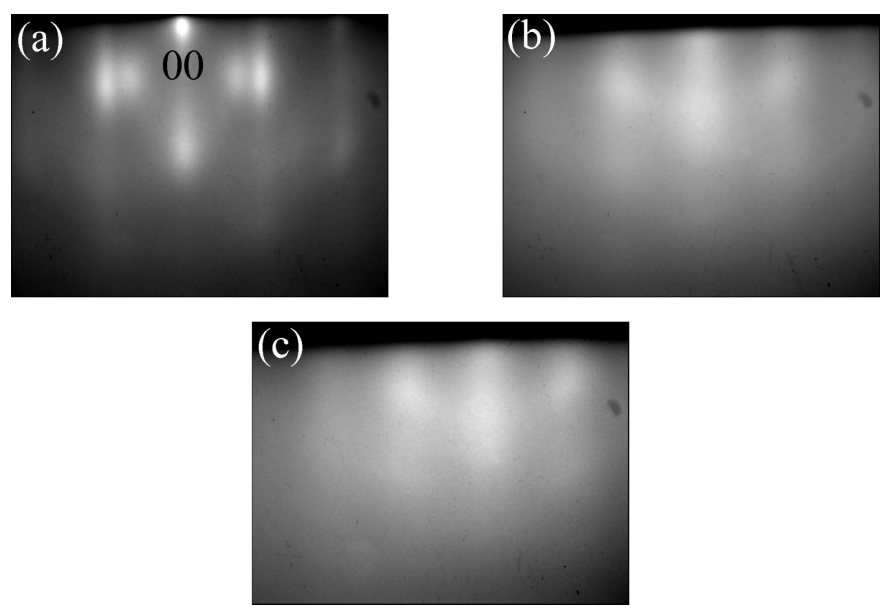

Figure 1

RHEED patterns obtained in the [110] direction of the substrate after growth of 6-9 nm-thick $\mathrm{Gd}_{2} \mathrm{O}_{3}$ at $250^{\circ} \mathrm{C}$ for different oxygen partial pressures: $(a)$ without additional oxygen $\left(5 \times 10^{-8}\right.$ mbar pressure during growth), $(b)$ with additional oxygen $\left(2 \times 10^{-7} \mathrm{mbar}\right)$ and $(c)$ with additional oxygen $\left(2 \times 10^{-7} \mathrm{mbar}\right)$ with a temperature ramp up during growth. pattern of the sample grown at $250^{\circ} \mathrm{C}$ [Fig. 1(b)]. This could be interpreted in terms of the suggestion that no recrystallization takes place and the early stage of growth is the defining factor of the later crystal structure and morphology.

HRXRD measurements were performed to determine the crystal structure and orientation of the layers. The symmetric $2 \theta / \omega$ geometry is used to identify the out-of-plane orientation of the $\mathrm{Gd}_{2} \mathrm{O}_{3}$ layers. Based on known data (Villars \& Cenzual, 2012; Wu et al., 2007), the observed peaks were identified using the software Vesta (Momma \& Izumi, 2011). Besides the $\mathrm{Si}(001)$ substrate reflections, there are only some weak additional reflections visible in the pattern shown in Fig. 2(a). The amplification of the forbidden Si002 reflection and the shoulder on the left-hand side can be interpreted as an effect of the so-called Umweganregung in silicon (Zaumseil, 2015). This effect is attributed to multiple diffractions in the silicon
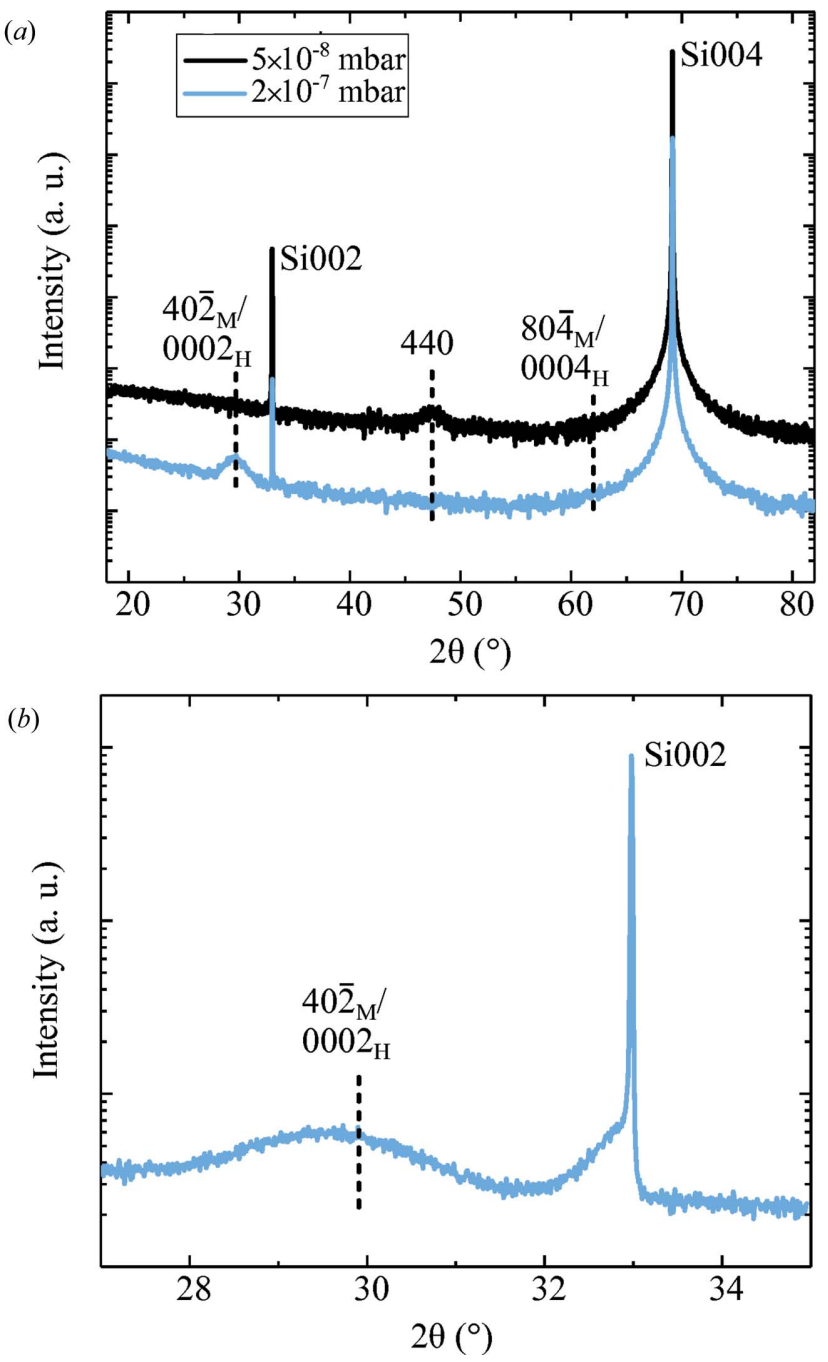

Figure 2

HRXRD measurements in symmetric $2 \theta / \omega$ geometry of $\mathrm{Gd}_{2} \mathrm{O}_{3}$ layers grown at $250^{\circ} \mathrm{C}$. (a) Without additional oxygen supply $\left(5 \times 10^{-8} \mathrm{mbar}\right)$ and with additional oxygen partial pressure $\left(2 \times 10^{-7}\right.$ mbar $)$. In $(b)$ a detailed symmetric $2 \theta / \omega$ measurement with improved signal to noise ratio of the reflection at $2 \theta \simeq 30^{\circ}$ from the symmetric $2 \theta / \omega$ measurement in $(a)$ is shown. The side intensity on the left side of the $\mathrm{Si}(002)$ reflection in $(b)$ could be attributed to Umweganregung (Zaumseil, 2015). 
and can occur in certain azimuthal orientations of the sample. Intensity as a consequence of multiple diffraction can appear if the Laue condition for at least three different net planes is fulfilled at the same time (Rossmanith, 2000; Renninger, 1937).

The HRXRD measurement of the sample grown at $250^{\circ} \mathrm{C}$ without additional oxygen supply and a growth pressure of $5 \times 10^{-8}$ mbar [Fig. 2(a)], reveals a broad reflection maximum at $2 \theta \simeq 47.5^{\circ}$. This reflection could be indexed as the 440 reflection of cubic $\mathrm{Gd}_{2} \mathrm{O}_{3}$ indicating a (110) orientation of the layer which agrees with the suggestion based on the observations in RHEED [Fig. 1(a)]. The symmetric $2 \theta / \omega$ measurement of the sample grown with additional oxygen supply [Fig. 2(a)] shows a broad reflection at $2 \theta \simeq 30^{\circ}$. The peak position is close to monoclinic $40 \overline{2}_{\mathrm{M}}$ or hexagonal $0002_{\mathrm{H}}$ reflections which have very similar $2 \theta$ values because of the similar crystal structure in the out-of-plane direction (Chang et al., 2010). Fig. 2(b) shows a detailed symmetric $2 \theta / \omega$ measurement with improved signal-to-noise ratio around the reflection at $2 \theta \simeq 30^{\circ}$ of the lower curve in Fig. 2(a).

A clear distinction between the hexagonal and the monoclinic crystal structure is not possible using the symmetric $2 \theta / \omega$ scan geometry. However, the atomic arrangements in monoclinic and hexagonal $\mathrm{Gd}_{2} \mathrm{O}_{3}$ differ significantly in azimuthal directions. Therefore, investigation of asymmetrical reflections should give more information on the real structure. However in our measurements, the asymmetrical reflections of the layers did not give any intensity. Another suitable way to identify the crystal structure of the $\mathrm{Gd}_{2} \mathrm{O}_{3}$ within the layer would be the application of GIXRD measurements, where diffraction from the in-plane net planes could be detected, as illustrated in Fig. 3. The advantage of this method is the very low incidence angle $\left(\simeq 0.3^{\circ}\right)$, so the beam penetrates only a few nanometres into the layer which makes this method very surface-sensitive.

In the GIXRD configuration only reflection of the net planes which are orthogonal to the net planes of the out-ofplane direction $(20 \overline{1})$ or (0001) (or almost orthogonal because

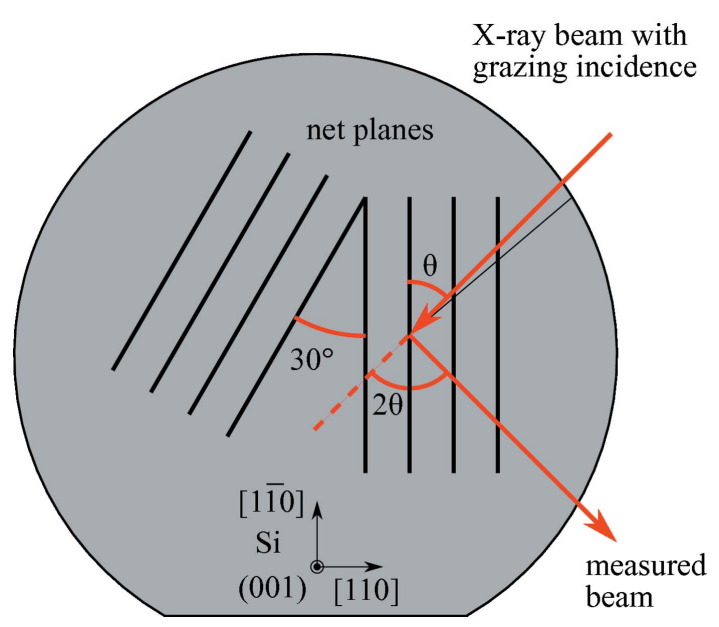

Figure 3

Schematic drawing of a grazing-incidence X-ray diffraction measurement (GIXRD). The straight lines represent in-plane net planes. of the peak broadening of the reflection) are detectable. Fig. 4 shows the surface projection of expected reflections from inplane net planes of the monoclinic and hexagonal structure, respectively.

The GIXRD measurements (Fig. 5) were performed in [110] in-plane direction of the substrate. Aside from the strong substrate Si220 peak a few other broad peaks are visible. The peaks correspond to reflections from the monoclinic (202),

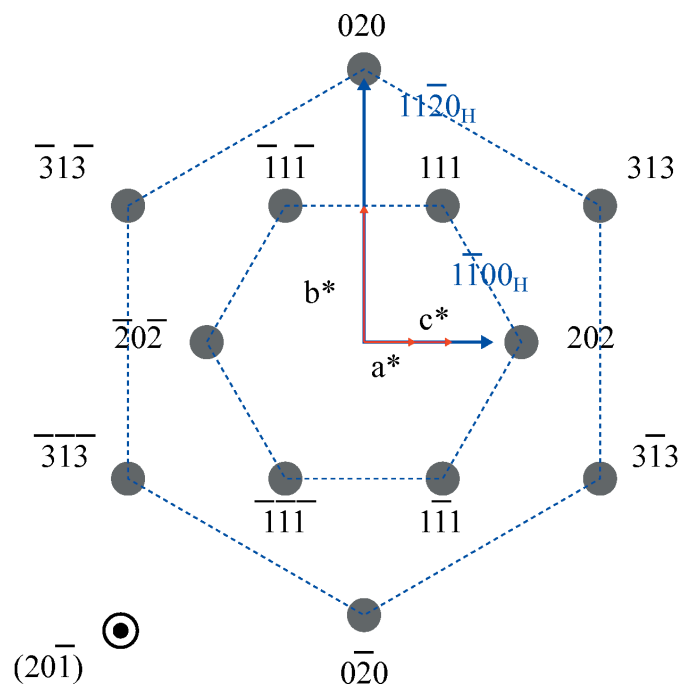

Figure 4

Projection of the in-plane net planes reflection of the monoclinic structure with an (201) orientation and the hexagonal structure with an (0001) orientation [according to Chang et al. (2010)], which could occur during GIXRD measurement. $a^{*}, b^{*}$ and $c^{*}$ are the reciprocal lattice vectors of the monoclinic structure. The hexagons represent the hexagonal lattice.

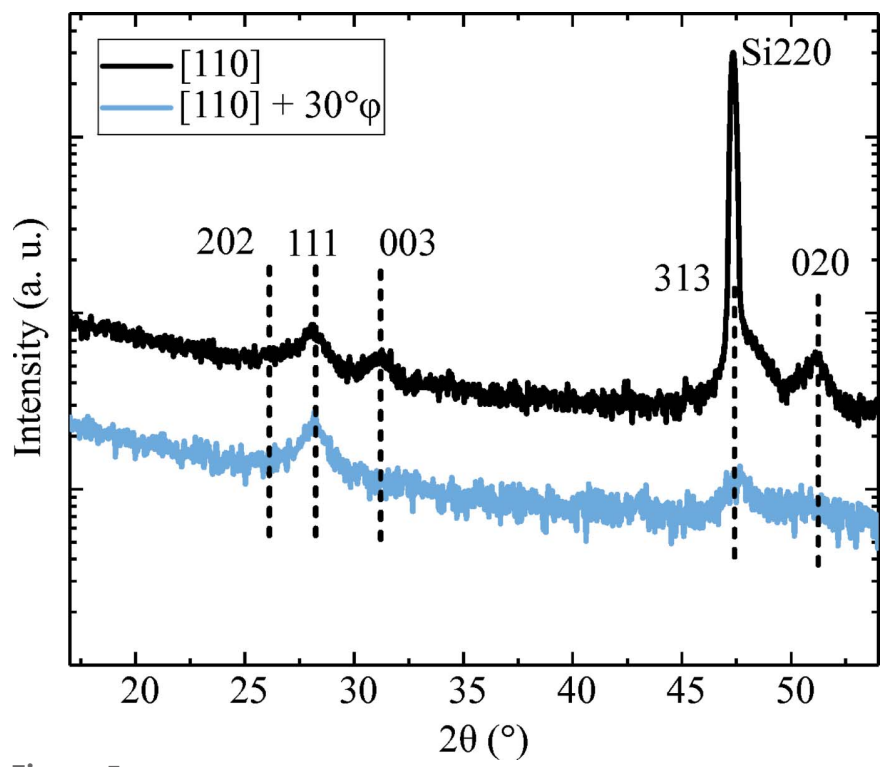

Figure 5

GIXRD measurements of the $\mathrm{Gd}_{2} \mathrm{O}_{3}$ layer grown at $250^{\circ} \mathrm{C}$ with additional oxygen partial pressure $\left(2 \times 10^{-7} \mathrm{mbar}\right)$ in the [110] in-plane direction and $30^{\circ}$ rotated to the [110] direction. The dashed lines indicate the calculated bulk values for peak positions corresponding to different net planes of the monoclinic phase. 
(111), (313) and (020) net planes, which proves that the crystal structure is monoclinic. Furthermore, the peaks represent reflections from net planes with different distances in one inplane direction, which proves the existence of different domains in the layer. This is depicted in Fig. 4, where the reflections for the observed diffraction peaks occur approximately $30^{\circ}$ rotated to each other, which indicates the growth in six rotational domains. However, the reflection around $2 \theta \simeq$ $31^{\circ}$ does not fit to a monoclinic reflection from an in-plane net plane orthogonal to the (201) direction. This peak could be interpreted as diffraction from the monoclinic (003) net planes. The lower curve in Fig. 5 shows a GIXRD measurement with an azimuthal rotation of $30^{\circ}$ with respect to the [110] direction of the substrate, which will be discussed later.

The in-plane structure was further investigated by azimuthal scans in GIXRD configuration (Fig. 6) to determine the symmetry of the crystal and the number and orientation of suggested domains. First, the sample was aligned on the 020 reflection in the in-plane [110] direction and the azimuthal angle $\varphi$ was changed while measuring the X-ray intensity. Reflections with a separation of $90^{\circ}$ appear [Fig. 6(a)] which hint at a fourfold symmetry of the layer and an alignment of the (020) planes parallel to the $\langle 110\rangle$ in-plane directions of the

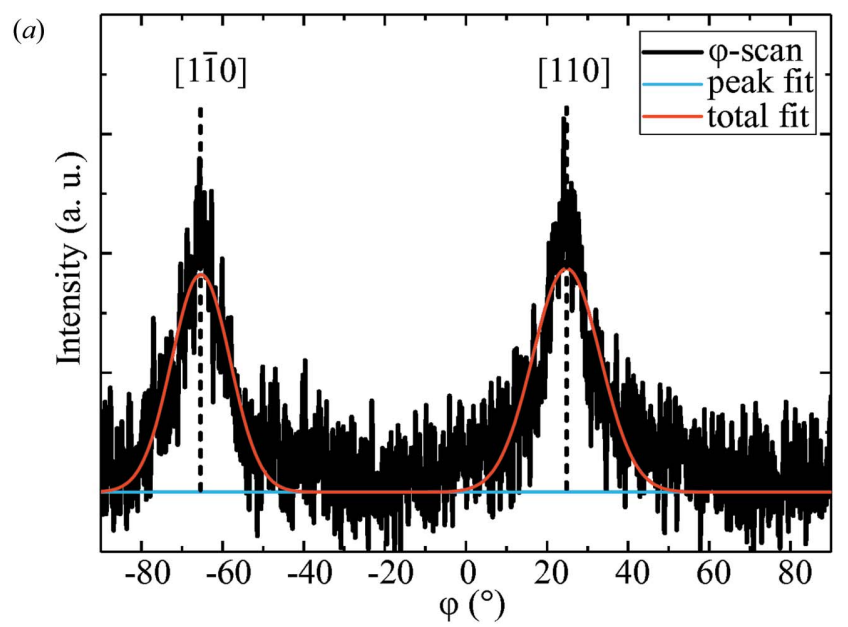

(b)

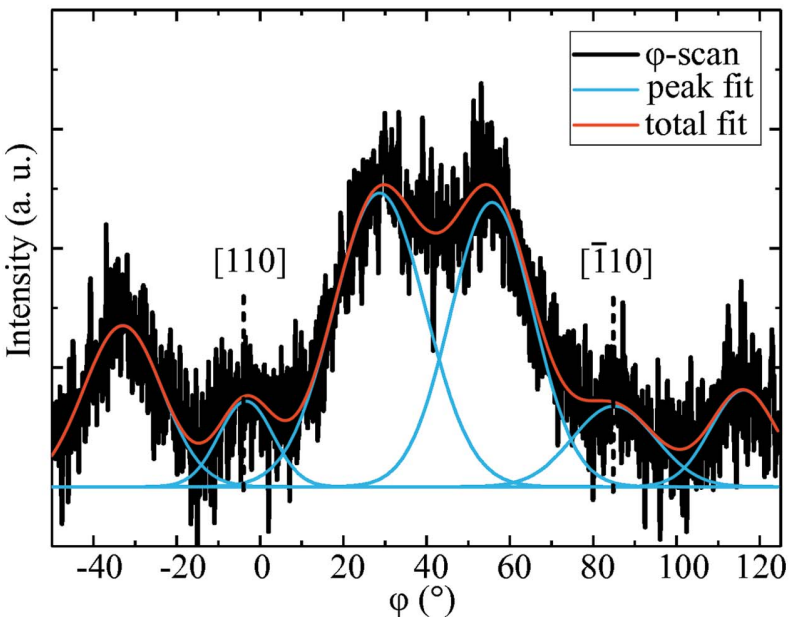

Figure 6

$\varphi$ scans in GIXRD configuration around (a) the 020 and $(b)$ the 111 reflections of the $\mathrm{Gd}_{2} \mathrm{O}_{3}$ layer.
Table 1

Epitaxial relationships of the different domains of the $\mathrm{Gd}_{2} \mathrm{O}_{3}$ with respect to the silicon substrate.

\begin{tabular}{ll}
\hline Domain & Epitaxial relationship \\
\hline $\mathrm{A}$ & $\mathrm{Gd}_{2} \mathrm{O}_{3}(20 \overline{1})[010]|| \mathrm{Si}(001)[1 \overline{1} 0]$ \\
$\mathrm{B}$ & $\mathrm{Gd}_{2} \mathrm{O}_{3}(20 \overline{1})[010]|| \mathrm{Si}(001)[110]$ \\
$\mathrm{C}$ & $\mathrm{Gd}_{2} \mathrm{O}_{3}(20 \overline{1})[111]|| \mathrm{Si}(001)[1 \overline{1} 0]$ \\
D & $\mathrm{Gd}_{2} \mathrm{O}_{3}(20 \overline{1})[313]|| \mathrm{Si}(001)[1 \overline{1} 0]$ \\
E & $\mathrm{Gd}_{2} \mathrm{O}_{3}(20 \overline{1})[313]|| \mathrm{Si}(001)[110]$ \\
F & $\mathrm{Gd}_{2} \mathrm{O}_{3}(20 \overline{1})[111]|| \mathrm{Si}(001)[110]$ \\
\hline
\end{tabular}

substrate. However, a single oriented monoclinic structure should only show peaks with a separation of $180^{\circ}$ according to the twofold symmetry of the (020) plane. One possible explanation could be the appearance of two orthogonal inplane domains. But this result does not match with the result of the GIXRD measurement. Therefore, an additional $\varphi$ scan was performed around the 111 reflection which shows a peak about every $30^{\circ}$ with different intensities [Fig. 6(b)] which agrees with the GIXRD measurement in Fig. 5 (upper curve). The highest intensities occur at rotations of around $30^{\circ}$ and $60^{\circ}$ with respect to the [110] direction of the substrate which would fit to the domains oriented along the $\langle 110\rangle$ directions of the substrate with the $(020)$ planes.

To determine the origin of the reflection at $2 \theta \simeq 31^{\circ}$ in Fig. 5 another $\varphi$ scan (not shown) was performed which shows peaks with a separation of $90^{\circ}$. The fourfold symmetry could only be explained by a monoclinic structure with two orthogonal inplane domains. Therefore, the monoclinic $\mathrm{Gd}_{2} \mathrm{O}_{3}$ layer contains additional domains with another orientation which is not visible in the symmetric $2 \theta / \omega$ scan.

To determine the in-plane structure finally, an additional GIXRD measurement was performed (Fig. 5) with $30^{\circ}$ rotation of $\varphi$ with respect to the [110] direction of the substrate. In this case only the 313 and 111 reflections are clearly visible.

Based on these studies, it can be clearly suggested that the $\mathrm{Gd}_{2} \mathrm{O}_{3}$ layer exhibits a monoclinic structure in $(20 \overline{1})$ orientation consisting in-plane of six rotational domains rotated against each other at about $30^{\circ}$. The different domains appear with different probability (different intensity), where two orthogonal domains oriented along the $\langle 110\rangle$ directions of the substrate with the (020) planes having the highest amount (the $\mathrm{A}$ and $\mathrm{B}$ domains in Fig. 7). The different domains and the orientation with respect to the silicon substrate are depicted in Fig. 7 and summarized in Table 1.

Next, the influence of a temperature ramp up from $250^{\circ} \mathrm{C}$ to $650^{\circ} \mathrm{C}$ during growth on the layer structure and orientation was investigated. Compared to the low-temperature growth the same peaks in symmetric $2 \theta / \omega$ measurement were observed [Fig. 8(a)] indicating that there is no influence of the temperature ramp up on the layer structure and orientation. The maximum of the $40 \overline{2}$ reflection, however, is slightly shifted towards a higher $2 \theta$ value [Fig. $8(b)$ ], which brings the maximum closer to the expected bulk value $\left(2 \theta \simeq 29.9^{\circ}\right)$. A peak shift to higher $2 \theta$ values could arise from relaxation within a tensile-stressed film. Thus, the peak shift towards higher $2 \theta$ value for the layer grown with a temperature ramp 
up could be interpreted in terms of a reduced stress compared to the layer grown at constant lower temperature.

Fig. 9 compares the overall surface morphology of the layers grown under different conditions, as seen using AFM. All AFM images show a very similar surface structure of spherical
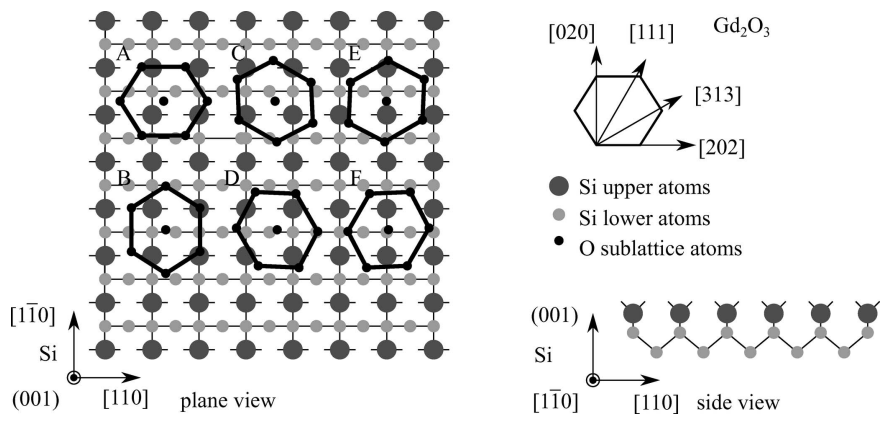

Figure 7

Schematic drawing (plane view) of the different oriented domains of the monoclinic $\mathrm{Gd}_{2} \mathrm{O}_{3}$ on the non-reconstructed $\mathrm{Si}(001)$ surface.

(a)

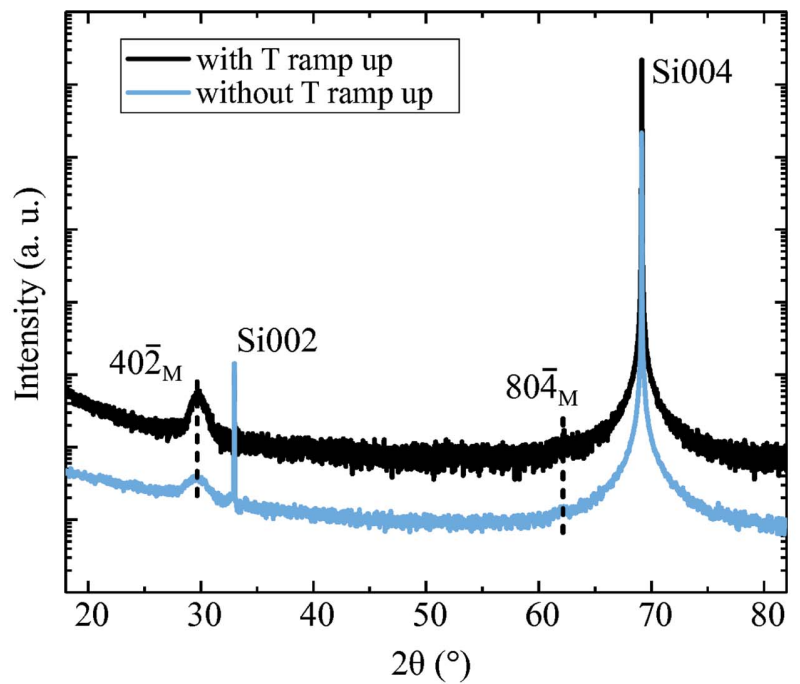

(b)

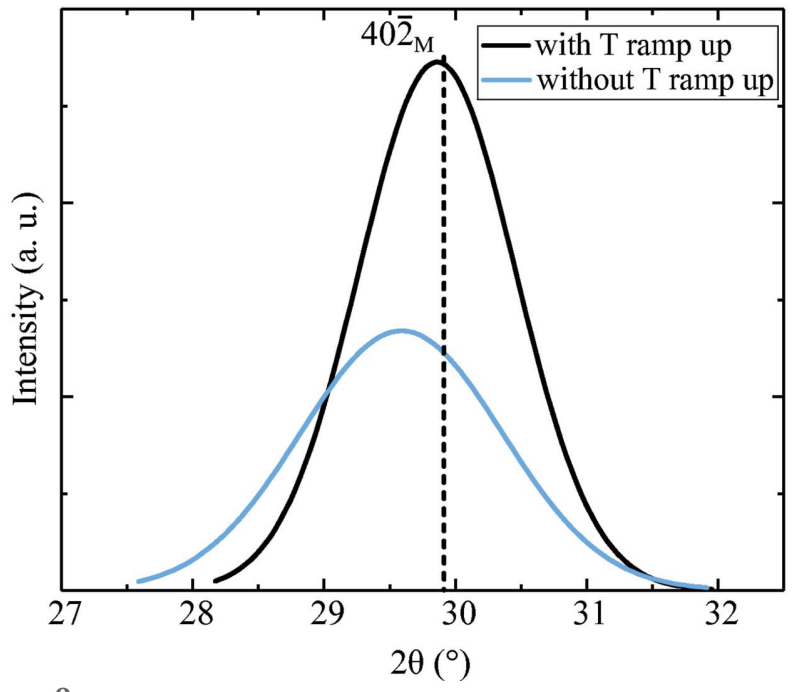

Figure 8

(a) Symmetric $2 \theta / \omega$ measurements of $\mathrm{Gd}_{2} \mathrm{O}_{3}$ layers grown at $250^{\circ} \mathrm{C}$ with and without a temperature ramp up during the growth. (b) Fit of the $40 \overline{2}$ reflection of both measurements.
Table 2

RMS roughness of the samples grown at $250^{\circ} \mathrm{C}$ at various oxygen partial pressures.

\begin{tabular}{lll}
\hline$p$ (mbar) & RMS roughness $(\mathrm{nm})$ & Supporting information \\
\hline $5 \times 10^{-8}$ & $0.1( \pm 0.01)$ & \\
$2 \times 10^{-7}$ & $0.09( \pm 0.02)$ & \\
$2 \times 10^{-7}$ & $0.09( \pm 0.02)$ & With temperature ramp up \\
\hline
\end{tabular}

particles with a diameter of only a few nanometres, indicating that the oxygen partial pressure has almost no influence on the surface morphology of the $\mathrm{Gd}_{2} \mathrm{O}_{3}$ layers grown at $250^{\circ} \mathrm{C}$ without and with a temperature ramp up starting from $250^{\circ} \mathrm{C}$. The RMS (root-mean square) roughness calculated with the software Gwyddion is also very similar in the range below $0.1 \mathrm{~nm}$ (Table 2).

\subsection{High-temperature growth}

High-temperature growth was performed at $850^{\circ} \mathrm{C}$. In this case all $\mathrm{Si}$ substrates exhibit a $(2 \times 1)$ surface reconstruction due to $\mathrm{Si}$ dimer formation. The $\mathrm{Gd}_{2} \mathrm{O}_{3}$ layer grown at $850^{\circ} \mathrm{C}$ and $2 \times 10^{-7}$ mbar oxygen partial pressure shows a sharp and spotty RHEED pattern [Fig. 10(a)], which indicates a single crystalline nature of the layer with rough surface morphology. The RHEED pattern of the sample grown with oxygen partial pressure of $5 \times 10^{-7} \mathrm{mbar}$ is almost identical [Fig. 10(b)]. In contrast to the samples grown at $250^{\circ} \mathrm{C}$ and $5 \times 10^{-8} \mathrm{mbar}$, which also shows (110) orientation, no double spots are visible in the RHEED pattern. Therefore, the growth of singledomain cubic $\mathrm{Gd}_{2} \mathrm{O}_{3}$ in the (110) orientation can be suggested.

The growth of cubic $\mathrm{Gd}_{2} \mathrm{O}_{3}$ in (110) orientation is confirmed by the symmetric $2 \theta / \omega$ measurement shown in Fig. 11(a). The curves have a broad intensity maximum at $2 \theta \simeq 47.5^{\circ}$ which belongs to the 440 reflection of the cubic structure of $\mathrm{Gd}_{2} \mathrm{O}_{3}$. For layers grown at lower oxygen partial pressure another

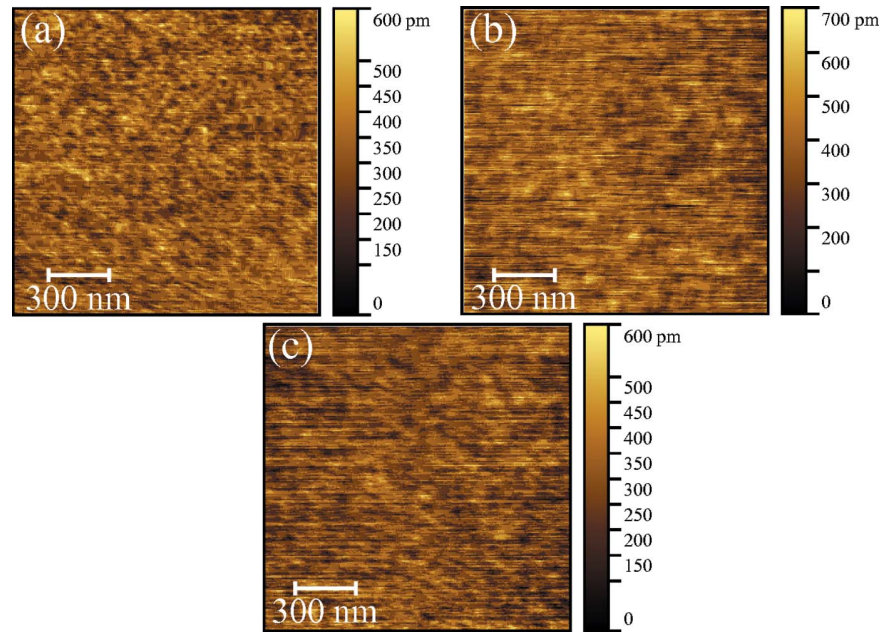

Figure 9

AFM images of $\mathrm{Gd}_{2} \mathrm{O}_{3}$ samples grown at $250^{\circ} \mathrm{C}$ with additional oxygen supply: (a) $2 \times 10^{-7}$ mbar, (b) without additional oxygen and $5 \times$ $10^{-8}$ mbar growth pressure $(c) 2 \times 10^{-7}$ mbar and temperature ramp up during growth. 
peak appears overlaying with the $\mathrm{Si}(002)$ reflection. For more detailed investigation a detailed symmetric $2 \theta / \omega$ scan with improved signal-to-noise ratio was performed [Fig. 11(b)]. The peak maximum reveals at $2 \theta \simeq 32^{\circ}$ with a full width at halfmaximum (FWHM) of $2.8^{\circ}$ which was fitted with a Gaussian function. This peak does not correspond to any known reflection of $\mathrm{Gd}_{2} \mathrm{O}_{3}$.
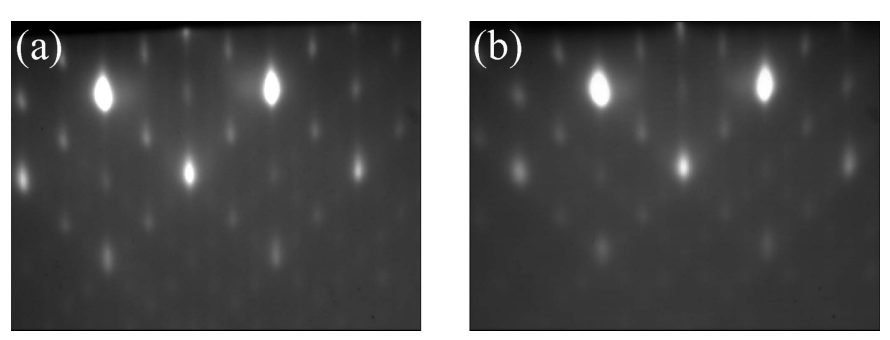

Figure 10

RHEED patterns obtained in the [110] direction of the substrate after growth of $\mathrm{Gd}_{2} \mathrm{O}_{3}$ on $\mathrm{Si}(001)$ at $850^{\circ} \mathrm{C}$ with an oxygen partial pressure of (a) $2 \times 10^{-7}$ mbar and (b) $5 \times 10^{-7}$ mbar.

(a)

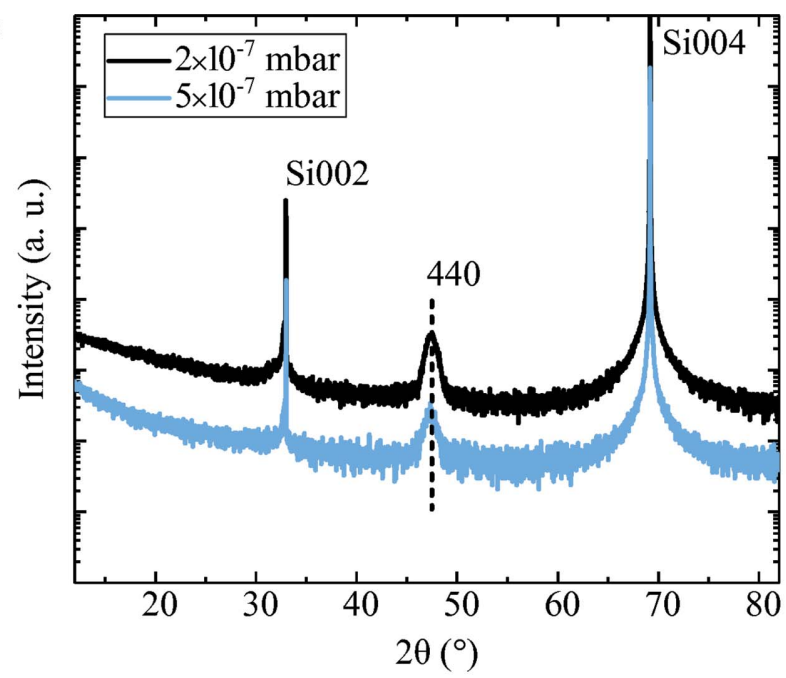

(b)

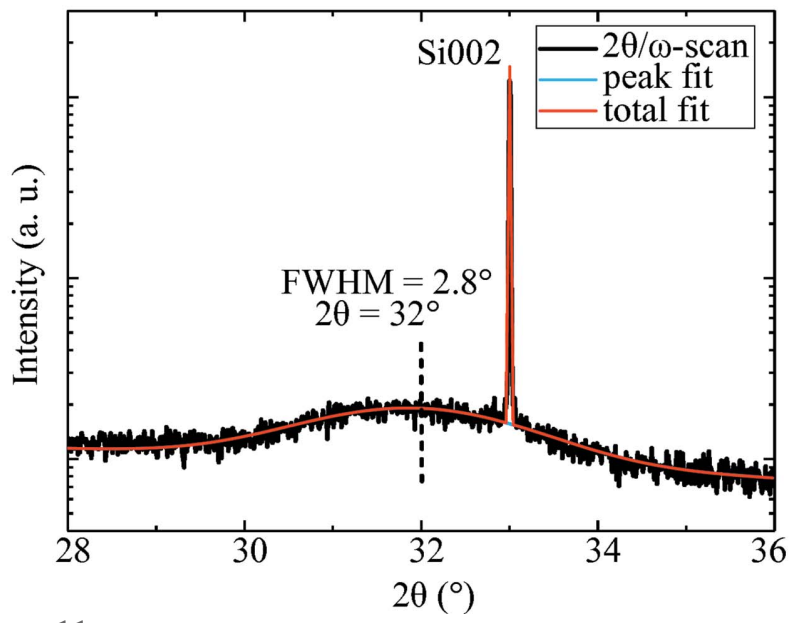

Figure 11

(a) Symmetric $2 \theta / \omega$ measurements of the $\mathrm{Gd}_{2} \mathrm{O}_{3}$ grown at $850^{\circ} \mathrm{C}$ with $2 \times$ $10^{-7}$ mbar and with $5 \times 10^{-7}$ mbar oxygen partial pressure. $(b)$ Detailed symmetric $2 \theta / \omega$ measurement with improved signal-to-noise ratio of the reflection around $32^{\circ}$ of the $\mathrm{Gd}_{2} \mathrm{O}_{3}$ grown at $850^{\circ} \mathrm{C}$ and $2 \times 10^{-7} \mathrm{mbar}$ oxygen partial pressure.
Moreover, in comparison to the literature (Zaumseil, 2015), the shape and position of the peak indicates no relationship with Umweganregung. One cause of the peak could be a distortion of the crystal, which would result in the formation of a tetragonal phase. However, a tetragonal phase is highly unlikely because it has only been reported (Semiletov et al., 1976) for non-stoichiometric $\mathrm{GdO}_{2}$, which is usually not stable. The appearance of this peak remains unclear at the moment.

The HRXRD scan for the sample grown at $850^{\circ} \mathrm{C}$ with a partial pressure of $5 \times 10^{-7}$ mbar shows only the 440 reflection [Fig. 11(a)], which means the layer is grown in (110) orientation. For further determination of the crystal structure of the layer grown at $850^{\circ} \mathrm{C}$, a $\varphi$ scan was performed. For this measurement, the sample was aligned in GIXRD configuration on the (400) net plane of the (110) oriented layer in the [110] in-plane direction of the substrate and the angle $\varphi$ was changed while measuring the intensity. The measurement (Fig. 12) shows two clear and sharp peaks with a separation of $90^{\circ}$ which indicates a fourfold symmetry. With respect to the (110) orientation of the layer and the twofold symmetry of the (110) plane, this indicates growth in two orthogonal in-plane domains. The two small peaks in between at a separation of $45^{\circ}$ could arise from the Si002 substrate reflections, which indicates a $45^{\circ}$ rotation of the layer with respect to the $\mathrm{Si}(001)$ substrate. The epitaxial relationship can be given therefore as $\mathrm{Gd}_{2} \mathrm{O}_{3}(110)[001]|| \mathrm{Si}(001)[110]$ for one domain and $\mathrm{Gd}_{2} \mathrm{O}_{3}(110)[001]|| \mathrm{Si}(001)[\overline{1} 10]$ for the other domain, respectively.

The alignment of the different domains with respect to the $\mathrm{Si}(001)$ substrate is schematically depicted in Fig. 13. In this context the appearance of orthogonal domains can be explained as follows. Since step-free $\mathrm{Si}$ substrates are not available, steps are always present at a substrate surface. On

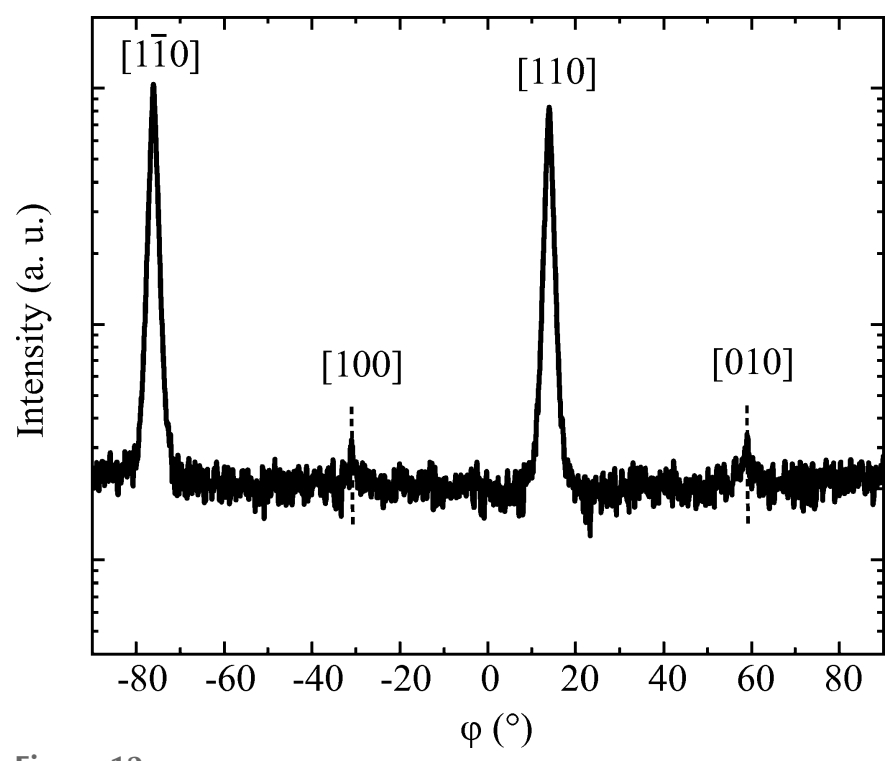

Figure 12

$\varphi$ scan in GIXRD configuration around the 400 reflection which indicates a growth in two orthogonal in-plane domains. The small peaks at a separation of $45^{\circ}$ from the higher intensity peaks probably result from $\mathrm{Si}(002)$ in-plane reflections. 
the $(2 \times 1)$ reconstructed $\mathrm{Si}(001)$ surface, dimer rows are formed which are orthogonal on adjacent terraces separated by single atom steps (parallel or orthogonal to the step edges). The Si-Si dimer bonds are shorter than the distance between the dimers in the row. $\mathrm{Gd}_{2} \mathrm{O}_{3}$ bonds to silicon via oxygen (Fissel et al., 2006b). On each terrace, the oxygen sublattice has a nearly perfect 1:1 lattice match in one direction and a 3:2 matching in the other direction which leads to two orthogonal domains (Osten et al., 2007).

The AFM image of the surface of the sample grown at $850^{\circ} \mathrm{C}$ and $2 \times 10^{-7}$ mbar [Fig. 14(a)] shows nanowire-like structures which are aligned in two different directions orthogonal to each other. These nanowire structures are oriented parallel and orthogonal to the wafer flat and thus arranged along the equivalent [110] directions on the substrate surface in accordance with the GIXRD measurements. The (a)

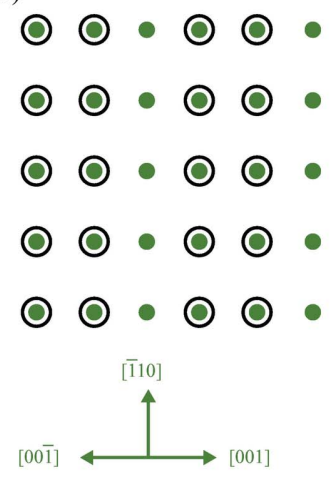

- (110) plane of cubic $\mathrm{Gd}_{2} \mathrm{O}_{3}$

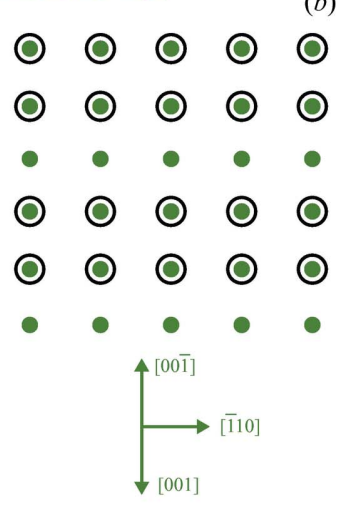

Figure 13

$(a, b)$ Schematic drawing of the arrangement of the (110) oriented $\mathrm{Gd}_{2} \mathrm{O}_{3}$ with respect to oriented $(2 \times 1)$ reconstructed $\mathrm{Si}(001)$ surfaces on the different terraces, where open circles represent the relaxed position of $\mathrm{Si}$ surface atoms within the $(2 \times 1)$ reconstruction on the $(001)$ plane. The full circles represent the position of the oxide atoms of $\mathrm{Gd}_{2} \mathrm{O}_{3}$ in the (110) orientation (Osten et al., 2007). (a)

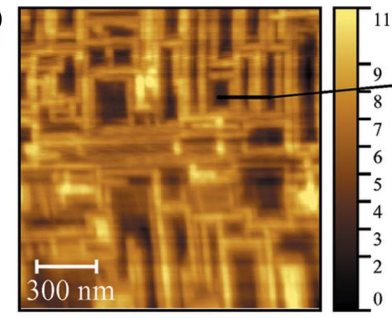

(b)

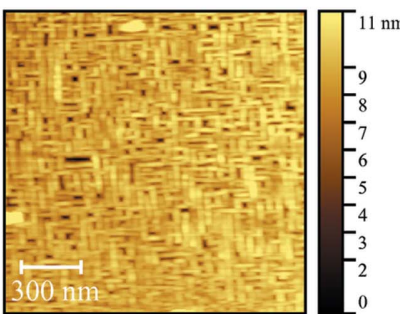

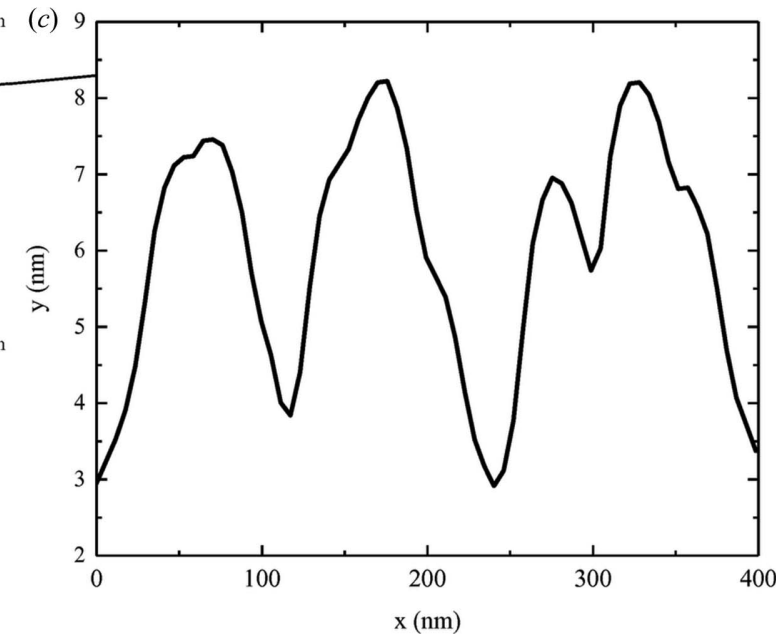

Figure 14

AFM images of $\mathrm{Gd}_{2} \mathrm{O}_{3}$ samples grown at $850^{\circ} \mathrm{C}$ with different oxygen partial pressures $(a) 2 \times$ $10^{-7}$ mbar and (b) $5 \times 10^{-7}$ mbar. In $(c)$ a line profile of the structures in the AFM image $(a)$ is shown.
Table 3

RMS roughness of $\mathrm{Gd}_{2} \mathrm{O}_{3}$ layers grown at $850^{\circ} \mathrm{C}$ at different oxygen partial pressure.

\begin{tabular}{ll}
\hline$p$ (mbar) & RMS roughness $(\mathrm{nm})$ \\
\hline $2 \times 10^{-7}$ & $2.43( \pm 0.43)$ \\
$5 \times 10^{-7}$ & $0.96( \pm 0.33)$ \\
\hline
\end{tabular}

AFM image of the layer grown at $850^{\circ} \mathrm{C}$ with an oxygen partial pressure of $5 \times 10^{-7}$ mbar [Fig. 14(b)] shows similar structures but with a higher density and a smaller length. This could be due to a lower mobility of adatoms in the presence of a larger amount of oxygen molecules on the surface. The average height of the nanowires was about $4-5 \mathrm{~nm}$, where the side walls are probably facets [Fig. 14(c)]. The surface RMS roughness is found to be reduced for higher oxygen partial pressure from around 2.4 to $1 \mathrm{~nm}$ (Table 3 ).

\section{Discussion}

The results presented in this work show a change of the crystal structure as well as change of surface morphology for $\mathrm{Gd}_{2} \mathrm{O}_{3}$ grown on $\mathrm{Si}(001)$ by varying the substrate temperature and the chemical oxygen potential. $\mathrm{Gd}_{2} \mathrm{O}_{3}$ grown at low temperature $\left(250^{\circ} \mathrm{C}\right)$ with additional oxygen supply tend to crystallize in the monoclinic phase with a $(20 \overline{1})$ orientation. The $\mathrm{Gd}_{2} \mathrm{O}_{3}$ becomes cubic with a (110) orientation without additional oxygen supply. Growth at high temperature $\left(850^{\circ} \mathrm{C}\right)$ is highly anisotropic and quasi nanowire-like $\mathrm{Gd}_{2} \mathrm{O}_{3}$ structures are formed with a (110) orientation. The results can be discussed and interpreted in terms of thermodynamic and kinetic effects, which we present in the following.

Grave et al. (2014) suggested a stress-induced phase transition in $\mathrm{Gd}_{2} \mathrm{O}_{3}$ thin films from monoclinic to the cubic phase with increasing temperature. Stress can be induced due to mismatch and thermal strain. The mismatch strain $\varepsilon_{\mathrm{mf}}$ and stress $\sigma_{\mathrm{mf}}$ between $\mathrm{Gd}_{2} \mathrm{O}_{3}$ and $\mathrm{Si}$ can be calculated using equations (1) and (2) below (Hull \& Bean, 1999), where $a_{\mathrm{L}}$ is the lattice constant of the layer material $\left[a_{\mathrm{L}}=\right.$ $a_{\mathrm{Gd} 2 \mathrm{O} 3}=1.0811 \mathrm{~nm}$ (Kwo et al., 2001)] and $a_{\mathrm{S}}$ the lattice constant of the substrate $\left[a_{\mathrm{S}}=2 a_{\mathrm{Si}}=1.0862 \mathrm{~nm}\right.$ (Hull \& Bean, 1999)]. The factor $G$ is the shear modulus $\left[G_{\mathrm{Gd} 2 \mathrm{O} 3}=\right.$ 57 GPa (Haglund \& Hunter, 1973)] and $v$ the Poisson ratio $\left[v_{\mathrm{Gd} 2 \mathrm{O} 3}=\right.$ 0.28 (Haglund \& Hunter, 1973)]

$$
\begin{gathered}
\varepsilon_{\mathrm{mf}}=2 \frac{a_{\mathrm{L}}-a_{\mathrm{S}}}{a_{\mathrm{L}}+a_{\mathrm{S}}}, \\
\sigma_{\mathrm{mf}}=2 G \varepsilon_{\mathrm{mf}} \frac{1+v}{1-v} .
\end{gathered}
$$

The mismatch strain for the $\mathrm{Gd}_{2} \mathrm{O}_{3} /$ $\mathrm{Si}(001)$ hetero-system reveals at room temperature to $\varepsilon_{\mathrm{mf}}=-0.47 \%$ 
and the mismatch stress to $\sigma_{\mathrm{mf}}=-0.95 \mathrm{GPa}$. Another stress can be implemented in the relaxed system due to different thermal expansion coefficients of the materials. The thermal strain $\varepsilon_{\mathrm{T}}$ can be calculated using equation (3) below (Hull \& Bean, 1999). The thermal expansion coefficient for $\mathrm{Gd}_{2} \mathrm{O}_{3}$ is $\alpha_{\mathrm{L}}(T)=\alpha_{\mathrm{Gd} 2 \mathrm{O} 3}(T)=7.77 \times 10^{-6} \mathrm{~K}^{-1}$ (Dargis et al., 2012) and for Si $\alpha_{\mathrm{S}}(T)=\alpha_{\mathrm{Si}}(T)=(2.7+0.0026 T) \times 10^{-6} \mathrm{~K}^{-1}$ (Hull \& Bean, 1999) and $\Delta T$ is the temperature difference between growth and room temperature. The thermal stress $\sigma_{\mathrm{T}}$ can be calculated analogue to the equation (2).

$$
\varepsilon_{\mathrm{T}}=\left[\alpha_{\mathrm{L}}(T)-\alpha_{\mathrm{S}}(T)\right] \Delta T .
$$

If we consider $\Delta T=230 \mathrm{~K}$ as the growth of monoclinic $\mathrm{Gd}_{2} \mathrm{O}_{3}$, the thermal strain is calculated to $\varepsilon_{\mathrm{T}}=0.1 \%$ and the thermal stress to $\sigma_{\mathrm{T}}=0.2 \mathrm{GPa}$.

The values estimated for the mismatch and thermal stress, however, are well below the stress necessary to initiate a phase transformation in $\mathrm{Gd}_{2} \mathrm{O}_{3}$. Zhang et al. (2008) reported a phase transition from cubic to monoclinic for $\mathrm{Gd}_{2} \mathrm{O}_{3}$ above $7 \mathrm{GPa}$ at $520 \mathrm{~K}$.

The structural phase transition could also be explained using thermodynamic considerations. Epitaxial layer growth is in simple terms the formation of nuclei (critical nuclei), the enlargement to islands and their subsequent coalescence to a layer. The size of the critical nuclei $r_{\mathrm{C}}$ is governed by the surface energy $\gamma_{\mathrm{S}}$ and the supersaturation according to equation (4) (Fletcher, 1958),

$$
r_{\mathrm{C}}=\frac{2 \gamma_{\mathrm{S}}}{\Delta G_{\mathrm{v}}} .
$$

$\Delta G_{\mathrm{v}}$ is the Gibbs free energy change per unit volume from the vapour to the solid phase, which is a function of supersaturation $S$ and described in equation (5), where $k$ is the Boltzmann constant, $\Omega$ the volume per atom, $p$ the growth pressure and $p_{0}$ the saturated vapour pressure (Fletcher, 1958)

$$
\Delta G_{\mathrm{v}}=\frac{k T}{\Omega} \ln \left(\frac{p}{p_{0}}\right)=\frac{k T}{\Omega} \ln (1+S) .
$$

Since the supersaturation depends on the supply (corresponding to the growth pressure $p$ ) and the temperature, which influences $p_{0}$, it can be suggested that for the same supply the critical nucleus is small at low temperature and large at high temperature, respectively. A change in oxygen supply results in a similar trend as a smaller critical nucleus (higher supersaturation) at higher oxygen partial pressure and a larger one at lower oxygen supply (lower supersaturation) according to equation (6), where the $\mathrm{s}$ and $\mathrm{g}$ refer to the solid and gas phase

$$
\mathrm{Gd}_{2} \mathrm{O}_{3}(\mathrm{~s}) \rightarrow 2 \mathrm{GdO}(\mathrm{g})+\mathrm{O}(\mathrm{g}) .
$$

At low temperature and lower oxygen partial pressure, the crystal structure of $\mathrm{Gd}_{2} \mathrm{O}_{3}$ was found to be cubic, whereas an increase in oxygen partial pressure results in the monoclinic structure. According to the growth conditions, this corresponds to a smaller critical nucleus for monoclinic $\mathrm{Gd}_{2} \mathrm{O}_{3}$ and a larger critical nucleus for cubic $\mathrm{Gd}_{2} \mathrm{O}_{3}$. At higher tempera- ture, which corresponds to a lower supersaturation, the cubic structure is always found.

Furthermore, an increase in temperature during growth has no influence on the resulting crystal structure. This means that the crystal structure of initially formed nuclei remains stable, even in the case of subsequent island growth and coalescence. This indicates a high activation barrier for the phase transition. This is probably due to the difference in coordination between gadolinium and oxygen in the different crystal structures of $\mathrm{Gd}_{2} \mathrm{O}_{3}$. For example, the cubic structure of $\mathrm{Gd}_{2} \mathrm{O}_{3}$, where the $\mathrm{Gd}$ atoms are coordinated by six oxygen atoms, can only transform to a sevenfold coordinated hexagonal phase via removal of some $\mathrm{O}$ atoms (Tracy et al., 2015).

The results suggest that the size of the critical nucleus has a significant influence on the crystal structure. The island size dependence of the crystal structure can be discussed within a thermodynamic approach, which is based on the GibbsThomson effect (Perez, 2005).

For $\mathrm{Gd}_{2} \mathrm{O}_{3}$ it is suggested that the monoclinic phase should appear for particle sizes below around $3 \mathrm{~nm}$ (Nicolas et al., 2006). The transition is explained due to the increasing surface tension compared to the volume which induces internal pressure. For $\mathrm{Gd}_{2} \mathrm{O}_{3}$ nanoparticles it is shown experimentally that a phase transition could be induced by high pressure from cubic to hexagonal and subsequently to the monoclinic phase, and the monoclinic phase can be stable after manufacturing at low temperatures (Chen et al., 2007; Jamnezhad \& Jafari, 2016). Zhang et al. (2008) reported on the appearance of the hexagonal phase above $10 \mathrm{GPa}$ at $520 \mathrm{~K}$. After the reduction of the pressure, $\mathrm{Gd}_{2} \mathrm{O}_{3}$ transforms into the monoclinic structure. This is a first-order solid-solid transition, where the hexagonal phase will spontaneously transform to the monoclinic phase because only a slight distortion is needed (Adachi \& Imanaka, 1998). No further transformation into the cubic phase by further reduction of the pressure was observed (Zhang et al., 2008).

For estimating the critical nucleus diameter $d_{\text {crit }}$ of $\mathrm{Gd}_{2} \mathrm{O}_{3}$ where a phase transition takes place, we can use an approach which is based on the Young-Laplace equation (7) (Bréchignac et al., 2007), where the hydrostatic pressure $P_{\text {int }}$ within a cluster is determined by the pressure outside $P_{\text {ext }}$, the surface energy $\gamma_{\mathrm{S}}$ and the diameter $d$. Since the growth in our experiments takes place in ultra-high vacuum we can neglect $P_{\text {ext }}$ :

$$
P_{\text {int }}=P_{\text {ext }}+\frac{4 \gamma_{\mathrm{s}}}{d} .
$$

In the literature there are only calculations of the surface energy for the hexagonal phase of $\mathrm{Gd}_{2} \mathrm{O}_{3}$. Liao et al. (2016) calculated the surface energy of hexagonal $\mathrm{Gd}_{2} \mathrm{O}_{3}$ for $\mathrm{Gd}$ - and O-terminated surfaces as a function of the oxygen chemical potential. For our calculation, we used an average value for the surface energy of $\gamma_{\mathrm{s}}=0.24 \mathrm{eV}^{-2} \simeq 3.85 \mathrm{~N} \mathrm{~m}^{-1}$.

Considering a critical pressure of $10 \mathrm{GPa}$ and a surface energy of $3.85 \mathrm{~N} \mathrm{~m}^{-1}$ the critical diameter for the formation of the hexagonal phase can be estimated with $d_{\text {crit }}=1.5 \mathrm{~nm}$. Nuclei with slightly larger size and a correspondingly smaller 
stress will crystallize in the monoclinic phase and should not transform into the cubic phase after nucleation and subsequent island growth (Zhang et al., 2008). Therefore, it is probable that the transformation to the monoclinic phase occurs when hexagonal islands grow further until the stress is reduced to the value where the monoclinic phase is exhausted. Such a hexagonal to monoclinic phase transition is reported for the growth of $\mathrm{Gd}_{2} \mathrm{O}_{3}$ on $\mathrm{GaN}$ and $\mathrm{SiC}$ (Chang et al., 2013; Fissel et al., 2006a). Moreover, a pressure-induced sizedependent phase transition is also found in many other nanosized materials, such as $\mathrm{Hf}, \mathrm{ZrO}, \mathrm{CdTe}, \mathrm{CdS}$ or CdSe (Xiong et al., 2013; Garvie, 1965; Wu et al., 2008; Haase \& Alivisatos, 1992; Schroeder \& Persans, 1996; Chen et al., 1997).

As already mentioned, the monoclinic phase is stable because no phase change occurs after increasing the temperature during the growth and cooling to room temperature. Thus, the thermodynamically most stable cubic bulk phase is not stable anymore and the crystal structure of the initially formed non-cubic islands determines the resulting layer structure. Therefore, the interface properties in contact with silicon are not the defining factor. Furthermore, the thermodynamically most stable surface is formed, which seems to be the (201) site of the monoclinic phase. Moellers et al. (2017) reported on the monoclinic phase of $\mathrm{Gd}_{2} \mathrm{O}_{3}$ grown on $\mathrm{Si}(111)$ with a $(20 \overline{1})$ orientation and six rotational domains, which is very similar to the reported structure of the $\mathrm{Gd}_{2} \mathrm{O}_{3}$ in our work. This observation supports the suggestion that the orientation of the observed monoclinic structure has only a slight dependence on the substrate orientation after the growth at low temperature.

Furthermore, the layers exhibit a domain structure which could be due to lattice structure mismatch between $\mathrm{Gd}_{2} \mathrm{O}_{3}$ and Si. According to Grundmann et al. (2010), in a heteroepitaxial system of a monoclinic layer with a twofold symmetry and cubic $\mathrm{Si}(001)$ substrate with a fourfold symmetry on the surface, the layer should only grow in two domains. In contrast, we observe six rotational domains which could be an indication of the formation of the hexagonal phase at the beginning of the growth at low temperatures.

For the high-temperature growth we suggest that the formation of nanowires is determined by kinetic and thermodynamic processes. The nanowires are oriented in two directions orthogonal to each other along the [110] directions on the substrate. The dimer rows from the $(2 \times 1)$ reconstruction of the $\mathrm{Si}(001)$ surface are also [110] oriented and, therefore, orthogonal to each other on adjacent terraces separated by single atomic steps. The [110] direction is also the direction of the good lattice matching between $\mathrm{Si}$ and $\mathrm{Gd}_{2} \mathrm{O}_{3}$, which probably results in an elongation in [110] rather than a further growth in the poorly matched [100] direction. Furthermore, the diffusion barrier parallel to the dimer rows is less than vertical (Srivastava \& Garrison, 1992). Therefore, gadolinium monoxide $(\mathrm{GdO})$, which is the dominant species during electron beam evaporation (Ames et al., 1967), will diffuse preferentially parallel to the dimer rows, attach to the surface and will, therefore, further elongate the islands to form nanowires. This is also supported by the much higher surface
Table 4

Growth parameters of all grown samples.

$T$ for temperature, $p$ for pressure, $d$ for layer thickness

\begin{tabular}{|c|c|c|c|c|c|}
\hline Sample & $\begin{array}{l}T \\
\left({ }^{\circ} \mathrm{C}\right)\end{array}$ & $\begin{array}{l}p \\
\text { (mbar) }\end{array}$ & $\begin{array}{l}d \\
(\mathrm{~nm})\end{array}$ & Crystal phase & $\begin{array}{l}\text { Supporting } \\
\text { information }\end{array}$ \\
\hline 1 & 250 & $5 \times 10^{-8}$ & 6 & Cubic (110) & $\begin{array}{l}\text { Without additional } \\
\mathrm{O}_{2}\end{array}$ \\
\hline 2 & 250 & $2 \times 10^{-7}$ & 6 & Monoclinic (201) & \\
\hline 3 & 250 & $2 \times 10^{-7}$ & 9 & Monoclinic (201) & $\begin{array}{l}\text { With temperature } \\
\text { ramp up }\end{array}$ \\
\hline 4 & 850 & $2 \times 10^{-7}$ & 8 & Mainly cubic (110) & Nanowires \\
\hline 5 & 850 & $5 \times 10^{-7}$ & 8 & Cubic (110) & Nanowires \\
\hline
\end{tabular}

mobility of the adatom clusters due to the higher temperature and the enhanced diffusion length along the dimer rows. An increase in oxygen partial pressure leads to a decrease in surface diffusion length because of a large number of adatoms on the surface. As a result, more and shorter nanowires will form.

Whereas for rare-earth silicides the growth of nanowire structures has been found (Liu \& Nogami, 2003), no such structures are reported yet for $\mathrm{Gd}_{2} \mathrm{O}_{3}$. However, the growth of $\mathrm{CaF}_{2}$ on $\mathrm{Si}(001)$ nanowires similar to those found in this investigation have been reported (Pasquali et al., 2001). Pasquali et al. $(2001,2005)$ reported on nanostripes formed out of $\mathrm{CaF}_{2}$ at high-temperature growth on $\mathrm{Si}(001)$ oriented along the [110] directions for sub-monolayer coverage. For thicker coverages the $\mathrm{CaF}_{2}$ forms ridged islands in just one [110] direction. Loretto et al. (1996) also reported quasi-onedimensional $\mathrm{CaF}_{2}$ islands on $\mathrm{Si}(001)$, which is even more similar to the results in our work. The $\mathrm{CaF}_{2}$ one-dimensional islands are oriented along the orthogonal [110] directions on the silicon (001) substrate and exhibit a width of a few nanometres and are elongated up to several microns. Loretto et al. (1996) have also shown the faceting character of these structures with mainly $\{111\}$ facets, which is also suggested in our work through AFM images.

The faceting of the nanowires is also reported for $\mathrm{CeO}_{2}$ grown on $\alpha-\mathrm{Al}_{2} \mathrm{O}_{3}$ substrates, where mostly $\{111\}$ facets on elongated islands are formed on the surface (Jacobsen et al., 1999). The (111) surface of rare-earth oxides is energetically the most favoured one and is therefore expected (Nolan et al., 2005; Tam et al., 2018). Faceting can occur when mass transport is sufficient to allow changes in orientation and can be achieved with a large surface diffusion (Williams \& Bartelt, 1989). At the growth temperature $\left(850^{\circ} \mathrm{C}\right)$, we can expect high diffusion lengths of atoms, which could explain the faceting.

In Table 4, the growth parameters and specification of all samples are summarized.

\section{Summary}

The structural and morphological properties of $\mathrm{Gd}_{2} \mathrm{O}_{3}$ grown with molecular beam epitaxy on $\mathrm{Si}(001)$ substrates under different conditions were precisely analysed via RHEED, $\mathrm{XRD}$ and AFM measurements. 
At low-temperature growth $\left(250^{\circ} \mathrm{C}\right), \mathrm{Gd}_{2} \mathrm{O}_{3}$ crystallizes in different phases depending on the oxygen chemical potential. Without an additional oxygen supply the crystal structure becomes a cubic bixbyite structure in space group $I a \overline{3}$ with a (110) orientation, whereas for an additional oxygen supply the monoclinic phase appears. The monoclinic structure with space group $C 2 / m$ grows mainly in two orthogonal in-plane domains with the epitaxial relationships $\quad \mathrm{Gd}_{2} \mathrm{O}_{3}(20 \overline{1})[010]|| \mathrm{Si}(001)[110] \quad$ and $\mathrm{Gd}_{2} \mathrm{O}_{3}(20 \overline{1})[010]|| \mathrm{Si}(001)[1 \overline{1} 0]$. We suggest the appearance of the monoclinic structure at low temperature and higher oxygen partial pressure is based on an increased internal pressure due to the surface curvature and the small radius of islands formed during deposition, which is usually called Gibbs-Thomson effect and is expressed by the YoungLaplace equation. The crystal structure within the small islands remains stable even during an increase in island size during further growth or an increase in temperature, indicating a large activation barrier for the crystal phase transition.

At high-temperature growth $\left(850^{\circ} \mathrm{C}\right), \mathrm{Gd}_{2} \mathrm{O}_{3}$ grows in cubic nanowires with a (110) orientation oriented along the $\langle 110\rangle$ directions. Increasing the oxygen partial pressure during the growth leads to a higher density and smaller length of the nanowires. The formation of nanowires is determined by a kinetic process where predominantly $\mathrm{GdO}$ will diffuse anisotropic in the direction along the dimer rows of the originally existing $(2 \times 1)$ reconstructed $\mathrm{Si}(001)$ surface and attach to the edge of already formed islands.

Thus, we illustrate a suitable way to tune the crystal structure, layer orientation and surface morphology of rare-earth oxides grown on silicon using molecular beam epitaxy.

\section{Acknowledgements}

We would like to thank Matthias Moellers for helpful discussions.

\section{Funding information}

The following funding is acknowledged: Minna-JamesHeineman foundation (scholarship to Philipp Gribisch).

\section{References}

Adachi, G.-Y., \& Imanaka, N. (1998). Chem. Rev. 98, 1479-1514. Ames, L. L., Walsh, P. N. \& White, D. (1967). J. Phys. Chem. 71, 27072718.

Azimi, G., Dhiman, R., Kwon, H.-M., Paxson, A. T. \& Varanasi, K. K. (2013). Nat. Mater. 12, 315-320.

Bierwagen, O., Proessdorf, A., Niehle, M., Grosse, F., Trampert, A. \& Klingsporn, M. (2013). Cryst. Growth Des. 13, 3645-3650.

Bréchignac, C., Houdy, P. \& Lahmani, M. (2007). Editors. Nanomaterials and Nanochemistry. Berlin, Heidelberg: Springer.

Chang, W. H., Chang, P., Lai, T. Y., Lee, Y. J., Kwo, J., Hsu, C.-H. \& Hong, M. (2010). Cryst. Growth Des. 10, 5117-5122.

Chang, W.-H., Wu, S.-Y., Lee, C.-H., Lai, T.-Y., Lee, Y.-J., Chang, P., Hsu, C.-H., Huang, T.-S., Kwo, J. R. \& Hong, M. (2013). Appl. Mater. Interfaces, 5, 1436-1441.
Charalampides, G., Vatalis K. I., Apostoplos, B. \& Ploutarch-Nikolas, B. (2015). Proc. Econ. Finance, 24, 126-135.

Chen, C., Herhold, A. B., Johnson, C. S. \& Alivisatos, A. P. (1997). Science, 276, 398-401.

Chen, H., He, C., Gao, C., Ma, Y., Zhang, J., Wang, X., Gao, S., Li, D., Kan, S. \& Zou, G. (2007). J. Phys. Condens. Matter, 19, 425229.

Chiang, T.-H., Wu, S.-Y., Huang, T.-S., Hsu, C.-H., Kwo, J. \& Hong, M. (2014). CrystEngComm, 16, 8457.

Chiu, Y. P., Huang, B. C., Shih, M. C., Shen, J. Y., Chang, P., Chang, C. S., Huang, M. L., Tsai, M.-H., Hong, M. \& Kwo, J. (2011). Appl. Phys. Lett. 99, 212101.

Dargis, R., Williams, D., Smith, R., Arkun, E., Roucka, R., Clark, A. \& Lebby, M. (2012). ECS J. Solid State Sci. Technol. 1, N24-N28.

Druon, F., Velázquez, M., Veber, P., Janicot, S., Viraphong, O., Buşe, G., Ahmed, M. A., Graf, T., Rytz, D. \& Georges, P. (2013). Opt. Lett. 38, 4146-4149.

Edge, L. F., Tian, W., Vaithyanathan, V., Heeg, T., Schlom, D., Klenov, D., Stemmer, S., Wang, J. \& Kim, M. J. (2008). ECS Transactions, 16, 213-227.

Fissel, A., Czernohorsky, M. \& Osten, H. J. (2006a). Superlattice Microstruct. 40, 551-556.

Fissel, A., Elassar, Z., Kirfel, O., Bugiel, E., Czernohorsky, M. \& Osten, H. J. (2006b). J. Appl. Phys. 99, 074105.

Fletcher, N. H. (1958). J. Chem. Phys. 29, 572-576.

Foëx, M. \& Traverse, J. P. (1966). Rev. Int. Hautes Temp. Réfract. 3, 429-453.

Garvie, R. C. (1965). J. Phys. Chem. 69, 1238-1243.

Gottlob, H. D. B., Echtermeyer, T., Mollenhauer, T., Efavi, J. K., Schmidt, M., Wahlbrink, T., Lemme, M. C., Kurz, H., Czernohorsky, M., Bugiel, E., Osten, H.-J. \& Fissel, A. (2006). Solid-State Electron. 50, 979-985.

Grave, D. A., Schmitt, M. P., Robinson, J. A. \& Wolfe, D. E. (2014). Surf. Coat. Technol. 242, 68-73.

Grundmann, M., Böntgen, T. \& Lorenz, M. (2010). Phys. Rev. Lett. 105, 146102.

Haase, M. \& Alivisatos, A. P. (1992). J. Phys. Chem. 96, 6756-6762.

Haglund, J. A. \& Hunter, O. (1973). J. Am. Ceram. Soc. 56, 327-330.

Hong, M., Lu, Z. H., Kwo, J., Kortan, A. R., Mannaerts, J. P., Krajewski, J. J., Hsieh, K. C., Chou, L. J. \& Cheng, K. Y. (2000). Appl. Phys. Lett. 76, 312-314.

Huang, A., Zheng, X., Xiao, Z., Wang, M., Di, Z. \& Chu, P. K. (2012). Chin. Sci. Bull. 57, 2872-2878.

Hubbard, K. J. \& Schlom, D. G. (1996). J. Mater. Res. 11, 2757-2776.

Hull, R. \& Bean, J. C. (1999). Editors. Germanium Silicon: Physics and Materials. San Diego: Academic Press.

Jacobsen, S. N., Helmersson, U., Erlandsson, R., Skårman, B. \& Wallenberg, L. R. (1999). Surf. Sci. 429, 22-33.

Jamnezhad, H. \& Jafari, M. (2016). J. Magn. Magn. Mater. 408, 164 167.

Kwo, J., Hong, M., Kortan, A. R., Queeney, K. L., Chabal, Y. J., Opila, R. L., Muller, D. A., Chu, S. N. G., Sapjeta, B. J., Lay, T. S., Mannaerts, J. P., Boone, T., Krautter, H. W., Krajewski, J. J., Sergnt, A. M. \& Rosamilia, J. M. (2001). J. Appl. Phys. 89, 3920-3927.

Kwo, J., Murphy, D. W., Hong, M., Mannaerts, J. P., Opila, R. L., Masaitis, R. L. \& Sergent, A. M. (1999). J. Vac. Sci. Technol. B, 17, 1294.

Li, Y., Chen, N., Zhou, J., Song, S., Liu, L., Yin, Z. \& Cai, C. (2004). J. Cryst. Growth, 265, 548-552.

Liao, K.-C., Wang, Y.-H., Liu, P.-L. \& Wang, H.-C. (2016). Opt. Quantum Electron. 48, 1-8.

Liu, B. Z. \& Nogami, J. (2003). Nanotechnology, 14, 873-877.

Loretto, D., Ross, F. M. \& Lucas, C. A. (1996). Appl. Phys. Lett. 68, 2363-2365.

Moellers, M., Margenfeld, C., Wietler, T. F. \& Osten, H. J. (2017). J. Cryst. Growth, 480, 141-144.

Molle, A., Wiemer, C. M. D. N. K., Bhuiyan, M. D. N. K., Tallarida, G. \& Fanciulli, M. (2008). J. Phys. Conf. Ser. 100, 042048.

Momma, K. \& Izumi, F. (2011). J. Appl. Cryst. 44, 1272-1276. 
Nicolas, D., Masenelli, B., Mélinon, P., Bernstein, E., Dujardin, C., Ledoux, G. \& Esnouf, C. (2006). J. Chem. Phys. 125, 171104.

Nolan, M., Grigoleit, S., Sayle, D. C., Parker, S. C. \& Watson, G. W. (2005). Surf. Sci. 576, 217-229.

Osten, H. J., Kühne, D., Laha, A., Czernohorsky, M., Bugiel, E. \& Fissel, A. (2007). J. Vac. Sci. Technol. B, 25, 1039.

Osten, H. J., Laha, A., Czernohorsky, M., Bugiel, E., Dargis, R. \& Fissel, A. (2008). Phys. Status Solidi A, 205, 695-707.

Pasquali, L., D'Addato, S., Selvaggi, G., Nannarone, S., Sokolov, N. S., Suturin, S. M. \& Zogg, H. (2001). Nanotechnology, 12, 403-408.

Pasquali, L., Suturin, S. M., Ulin, V. P., Sokolov, N. S., Selvaggi, G., Giglia, A., Mahne, N., Pedio, M. \& Nannarone, S. (2005). Phys. Rev. $B, 72,045448$.

Perez, M. (2005). Scr. Mater. 52, 709-712.

Renninger, M. (1937). Z. Phys. 106, 141-176.

Rétot, H., Bessière, A., Viana, B. \& Galtayries, A. (2011). J. Appl. Phys. 109, 123518.

Rossmanith, E. (2000). J. Appl. Cryst. 33, 921-927.

Schroeder, J. \& Persans, P. D. (1996). J. Lumin. 70, 69-84.

Semiletov, S. A., Imamov, R. M., Ragimli, N. A. \& Man, L. I. (1976). Thin Solid Films, 32, 325-328.

Srivastava, D. \& Garrison, B. J. (1992). Phys. Rev. B, 46, 14721479.

Tam, J., Feng, B., Ikuhara, Y., Ohta, H. \& Erb, U. (2018). J. Mater. Chem. A, 6, 18384-18388.

Tanaka, T., Kuzuhara, M., Watada, M. \& Oshitani, M. (2006). J. Alloys Compd. 408-412, 323-326.
Tracy, C. L., Lang, M., Zhang, F., Trautmann, C. \& Ewing, R. C. (2015). Phys. Rev. B, 92, 174101.

Villars, P. \& Cenzual, K. (2012). $\mathrm{Gd}_{2} \mathrm{O}_{3} \mathrm{C}$ phase $\left(\mathrm{Gd}_{2} \mathrm{O}_{3} \mathrm{rt}\right)$ Crystal Structure: Datasheet from Pauling File Multinaries Edition - 2012 in SpringerMaterials (https://materials.springer.com/isp/crystallographic/docs/sd_1627282). Springer-Verlag Berlin Heidelberg \& Material Phases Data System (MPDS), Switzerland \& National Institute for Materials Science (NIMS), Japan.

Wang, R. G., Sama, V., Li, D. Q. \& Mutinda, S. I. (2012). Adv. Mater. Res. 512-515, 1624-1629.

Weber, R., Tangeman, J. A., Nordine, P. C., Scheunemann, R. N., Hiera, K. J. \& Ray, C. S. (2004). J. Non-Cryst. Solids, 345-346, 359365.

Williams, E. D. \& Bartelt, N. C. (1989). Ultramicroscopy, 31, 36-48.

Wu, B., Zinkevich, M., Aldinger, F., Wen, D. \& Chen, L. (2007). J. Solid State Chem. 180, 3280-3287.

Wu, F., Zaug, J. M., Young, C. E. \& Zhang, J. Z. (2008). J. Nanosci. Nanotechnol. 8, 6528-6532.

Xiang, W. F., Ni, H. \& Lu, H. B. (2013). Appl. Phys. A, 110, $423-$ 426.

Xiong, Y.-H., Tu, H.-L., Du, J., Wei, F., Zhang, X.-Q., Yang, M.-M., Zhao, H.-B., Chen, D.-P. \& Wang, W.-W. (2013). Appl. Surf. Sci. 283, 554-558.

Zaumseil, P. (2015). J. Appl. Cryst. 48, 528-532.

Zhang, F. X., Lang, M., Wang, J. W., Becker, U. \& Ewing, R. C. (2008). Phys. Rev. B, 78, 064114.

Zinkevich, M. (2007). Prog. Mater. Sci. 52, 597-647. 